\title{
Self-efficacy and entrepreneurial intention : the mediation effect of self-regulation
}

\begin{abstract}
Specifying the mechanism through which perceived self-efficacy affects one's behavior has been one of the main concerns of researchers and educators particularly in entrepreneurship domain due to the critical role that entrepreneurial self-efficacy plays in motivating and enabling individuals to establish a new venture. This study examines the relationship between entrepreneurial self-efficacy, self-regulation and entrepreneurial intention using Bandura's structural path model for the constructs. The sample was composed of 722 public and private Malaysian university students. The results revealed that students' entrepreneurial selfefficacy has the most significant and positive impact on their intention to become an entrepreneur. More specifically, entrepreneurial self-efficacy highly affects students' entrepreneurial intention both directly and indirectly. Furthermore, self-regulation partially mediates the relationship between entrepreneurial self-efficacy and students' entrepreneurial intention. Implications of these findings for entrepreneurship research and education are discussed
\end{abstract}

Keyword: Entrepreneurial self efficacy; Self regulation; Entrepreneurial intention; University student 